07,12

\title{
Образование нанокристаллов кремния при трении
}

\author{
(C) В.И. Веттегрень, Р.И. Мамалимов, И.П. Щербаков, В.Б. Кулик \\ Физико-технический институт им. А.Ф. Иофрфе РАН, \\ Санкт-Петербург, Россия \\ E-mail: Victor.Vettegren@mail.ioffe.ru
}

Поступила в Редакцию 26 декабря 2019 г.

В окончательной редакции 26 декабря 2019 г.

Принята к публикации 3 марта 2020 г.

\begin{abstract}
При помощи триболюминесценции (TL) установлено, что в процессе трения монокристалла кремния $(\mathrm{Si})$ образуются нанокристаллы - ncSi с линейными размерами $\approx 4 \mathrm{~nm}$. Исследована временная зависимость интенсивности сигналов TL. Она состоит из множества наложенных друг на друга сигналов. Анализ их динамики показал, что нанокристаллы располагаются на берегах микротрещин, образующихся при разрушении. Одновременно из области трения вылетает порошок. При помощи фотолюминесцентной (PL) и рамановской спектроскопии определен размер нанокристаллов кремния в порошке. Он составил $\approx 2.2 \mathrm{~nm}$. Вероятно, за время между трением и получением рамановских и PL спектров (несколько часов) происходит дальнейший рост микротрещин, что приводит к уменьшению размеров нанокристаллов в 2 раза.
\end{abstract}

Ключевые слова: трение, размеры нанокристаллов, люминесценция.

DOI: 10.21883/FTT.2020.07.49475.041

\section{1. Введение}

В настоящее время популярным методом получения $\mathrm{ncSi}$ является электрохимическое травление с последующим размолом полученного при этом пористого кремния $[1,2]$. В последнее время для этой цели начали размалывать монокристаллы кремния в шаровых мельницах [2]. В этом методе монокристаллы подвергаются ударам и трению, что приводит к их измельчению до наноразмеров. Структура, полученных таким способом, нанокристаллов исследована методами PL и рамановской спектроскопии, электронной микроскопии, рентгеновской дифракции и др. [3-5]. Механизм и динамика процесса измельчения до последнего времени остался не исследованным.

В настоящей работе порошок нанокристаллов $\mathrm{ncSi}$ получен не размолом, а при трении монокристалла $\mathrm{Si}$ о шероховатый стальной диск, и исследован механизм и динамика процесса измельчения, определены размеры ncSi.

\section{2. Объект и методы исследования}

Для исследования при трении построена установка, показанная на рис. 1. Образцы представляли собой цилиндры из монокристалла кремния диаметром 30, высотой $20 \mathrm{~mm}$, которые прижимали к стальной шероховатой пластине, прикрепленной к электромотору.

После включения электромотора возникала TL. Ee спектр зарегистрирован оптоволоконным спектрометром AvaSpec-ULSi2048L-USB2 OE.

Для исследования временной зависимости интенсивности сигналов TL излучение кварцевой линзой фокусировалось на поверхность фотоэлектронного умножителя
РЕМ-136. Электрическое напряжение на его выходе подавалось на вход аналогово-цифрового преобразователя ADS-3112 фирмы „АКТАКОМ“. Напряжение на выходе ADS через каждые 2 ns записывалось в память компьютера.

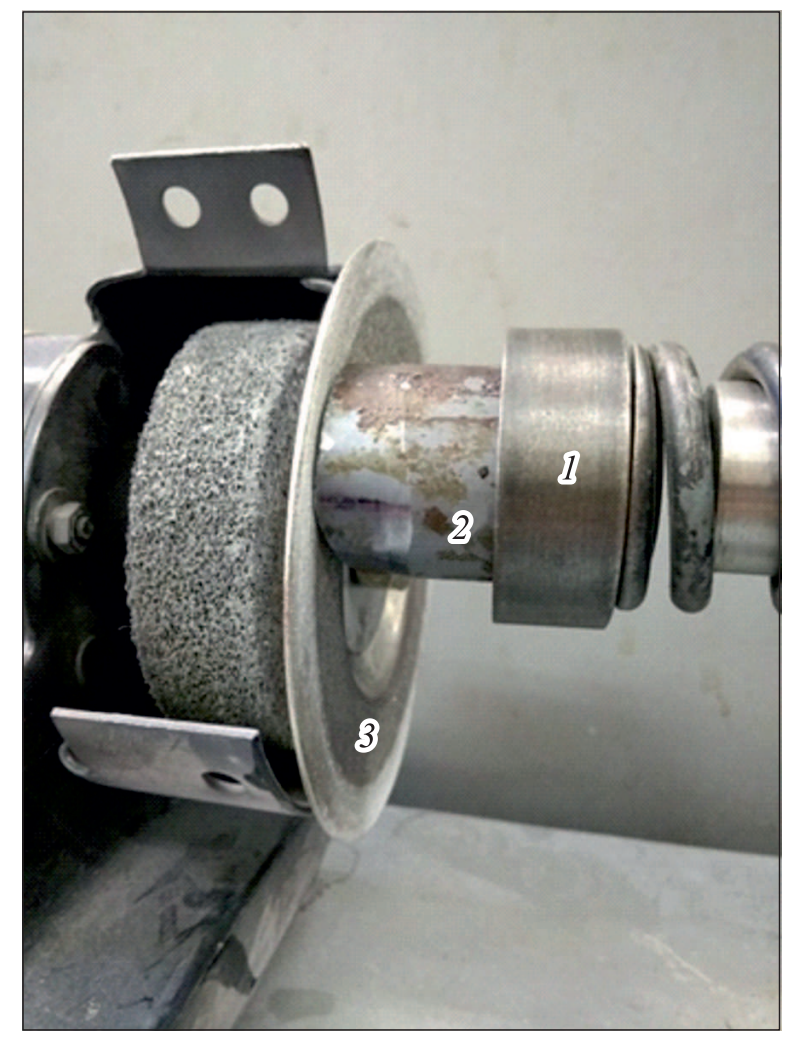

Рис. 1. Фотография узла трения: 1 - держатель образца; 2 кристалл кремния; 3 - стальной диск. 
Одновременно из зоны трения вылетал порошок. Спектры PL порошка возбуждали ультрафиолетовым светодиодом UVTOP280TO39HS (энергия излучения $4,35 \mathrm{eV})$ и регистрировали спектрометром AvaSpecULSi2048L-USB2 OE. Рамановские спектры порошка кремния возбуждали аргоновым лазером $\mathrm{Ar}^{++} 16508$ (Spectra Physics), линия $488.0 \mathrm{~nm}$, и записывали на спектрометре Ramalog 5. Угол рассеяния - $180^{\circ}$.

\section{3. Спектры TL кремния при трении и PL eго порошка}

Спектр TL при трении показан на рис. 2. В нем наблюдается полоса $\approx 1.62 \mathrm{eV}$. Появление этой полосы вызвано конфайнментом [6-8], т. е. увеличением ширины запрещенной зоны и нарушением закона сохранения импульса. Согласно [6-8], энергия максимума $\approx 1.62 \mathrm{eV}$, соответствует нанокристаллам ncSi с линейными размерами $\approx 4 \mathrm{~nm}$.

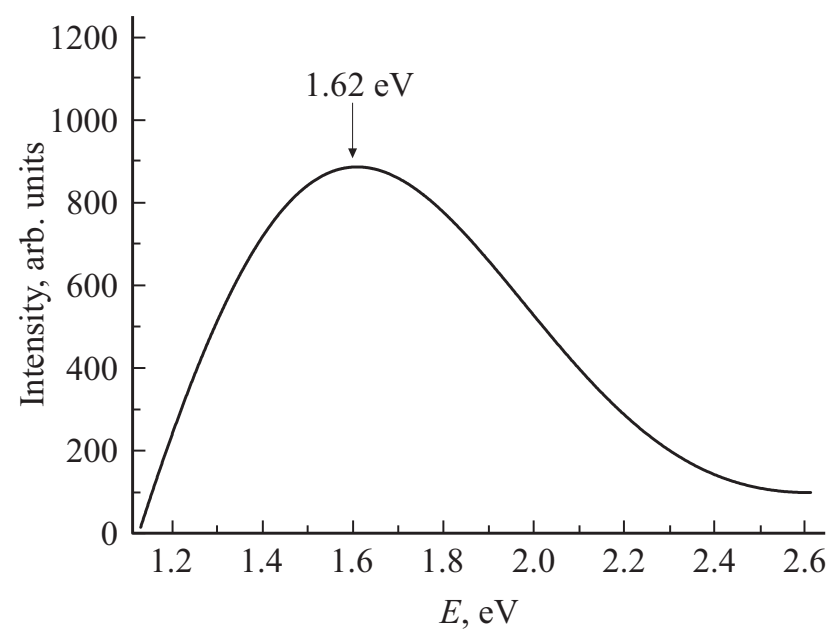

Pис. 2. Спектр TL при трении кварца о стальной вращающийся диск.

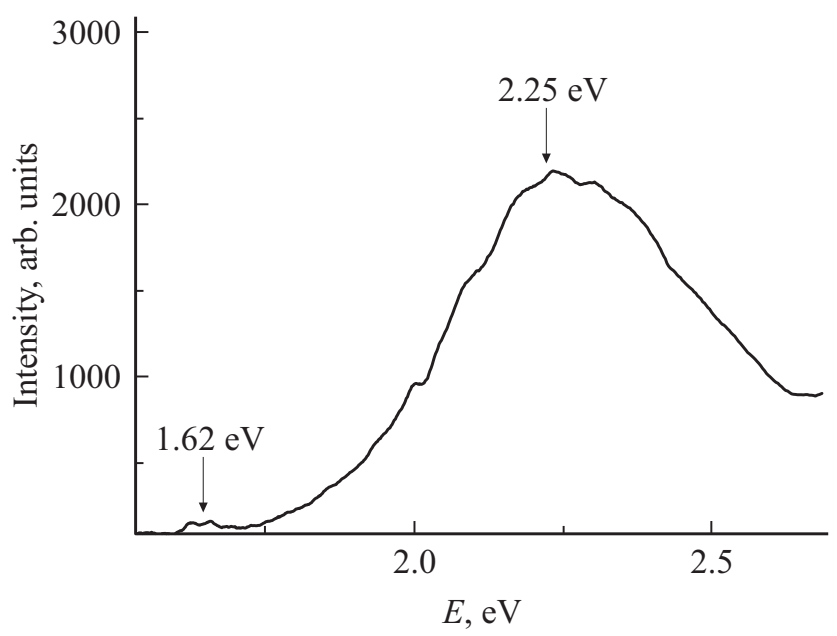

Рис. 3. Спектр PL порошка кремния.

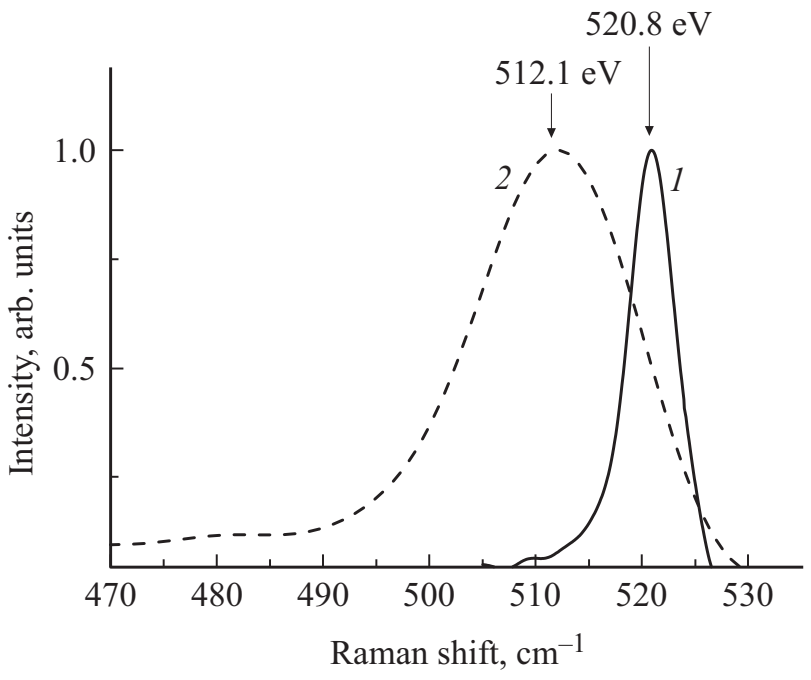

Рис. 4. Рамановский спектр монокристалла кремния (1) и порошка из него (2).

B спектрах PL порошка (рис. 3) наблюдали 2 полосы: интенсивная - с максимумом при $2.25 \mathrm{eV}$ и слабая $\approx 1.62 \mathrm{eV}$, интенсивность которой в $\approx 10^{3}$ раз меньше. Интенсивная полоса $2.25 \mathrm{eV}$, согласно [6-8], соответствует нанокристаллам кремния, размер которых не превышает $2.3 \mathrm{~nm}$. Существование слабой полосы показывает, что в порошке осталось небольшое количество кристаллов кремния, размер которых составляет $\approx 4 \mathrm{~nm}$.

\section{4. Рамановский спектр порошка кремния}

На рис. 4 показана полоса $520.8 \mathrm{~cm}^{-1}$ в рамановском спектре монокристалла кремния. Она соответствует поперечным колебаниям его кристаллической решетки [9].

В спектре порошка максимум этой полосы смещен в сторону низких частот на $\approx 8.7 \mathrm{~cm}^{-1}$, одновременно полоса неоднородно уширена с этой же стороны. Этот эффект также вызван конфайнментом $[10,11]$. В этом случае зависимость интенсивности от рамановского смещения имеет вид $[10,11]$ :

$$
I(v) \cong \int \frac{|C(0, q)|^{2} d^{3} q}{(v-v(q))^{2}+\left(\Gamma_{0} / 2\right)^{2}},
$$

где $v(q)$ - дисперсия, $C\left(q_{0}, q\right)$ - коэффициенты Фурье волновой функции $\Psi\left(\mathbf{q}_{0}, \mathbf{r}\right)$ :

$$
C\left(q_{0}, q\right)=\frac{1}{(2 \pi)^{3}} \int \Psi\left(\mathbf{q}_{0}, \mathbf{r}\right) \exp \left(-i \mathbf{q}_{0} \mathbf{r}\right) d^{3} r
$$

$\mathbf{q}_{0}$ - волновой вектор фонона исследуемого колебания для кристалла макроскопических размеров, $\mathbf{r}$ - вектор, величина которого равна расстоянию от точки, в которой амплитуда колебаний имеет наибольшее значение. 
В предположении, что нанокристаллы кремния имеют форму сферы, выражение (3) можно переписать в следующем виде [11]:

$$
|C(0, q)|^{2} \approx \frac{\sin ^{2}\left(-\frac{-\pi q d}{a}\right)}{\left[1-\left(\frac{q d}{a}\right)^{2}\right]^{2}},
$$

где $d$ - диаметр нанокристалла, $a$ - постоянная решетки (для $\mathrm{Si}-a=0.54 \mathrm{~nm}[12]$ ).

Для исследуемого колебания зависимость рамановского смещения $v(q)$ от волнового вектора фонона q имеет вид [13]:

$$
v(q) \approx v_{0}-12 q^{2}
$$

где $v_{0}$ - рамановское смещение для кристалла макроскопических размеров.

Используя выражения (2)-(4), мы подбирали значения частоты максимума $v_{0}$ и диаметра нанокристалла $d$, которые наилучшим образом описывают форму полос. Оказалось, что диаметр нанокристаллов кремния в порошке составляет $\approx 2.2 \mathrm{~nm}$, что совпадает с размерами нанокристаллов $\mathrm{ncSi}$, найденными из анализа спектра PL.

Вероятно, из-за больших внутренних напряжений, за время после трения до записи рамановских и PL спектров (несколько часов), более 90\% частиц порошка растрескивается, и размер нанокристаллов уменьшается в $\approx 2$ раза.

\section{5. Динамика образования источников люминесценции}

На рис. 5 приведена временная зависимость интенсивности сигналов TL при трении образца кремния о шероховатый стальной диск. Она состоит из множества наложенных друг на друга сигналов TL. Рассмотрение

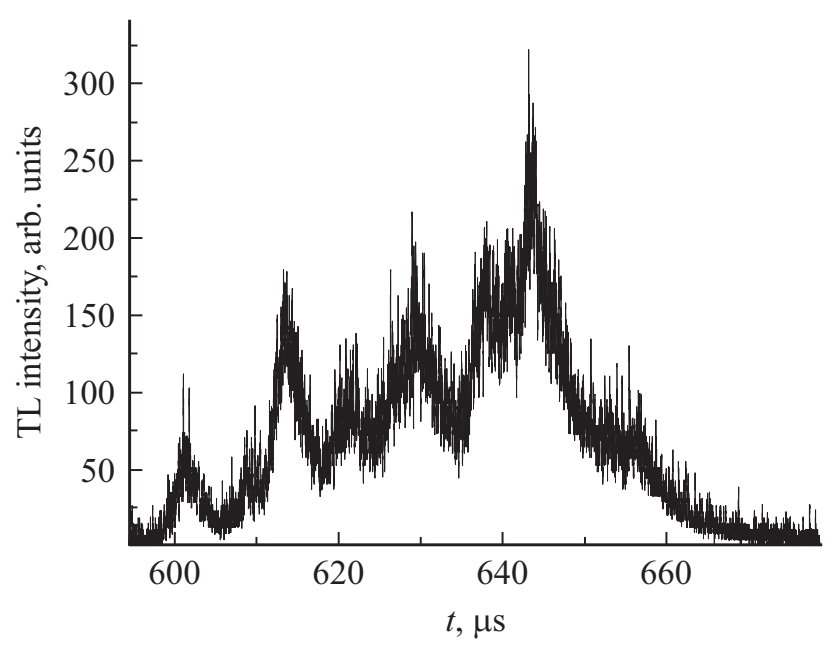

Рис. 5. Временная зависимость сигналов TL при трении.

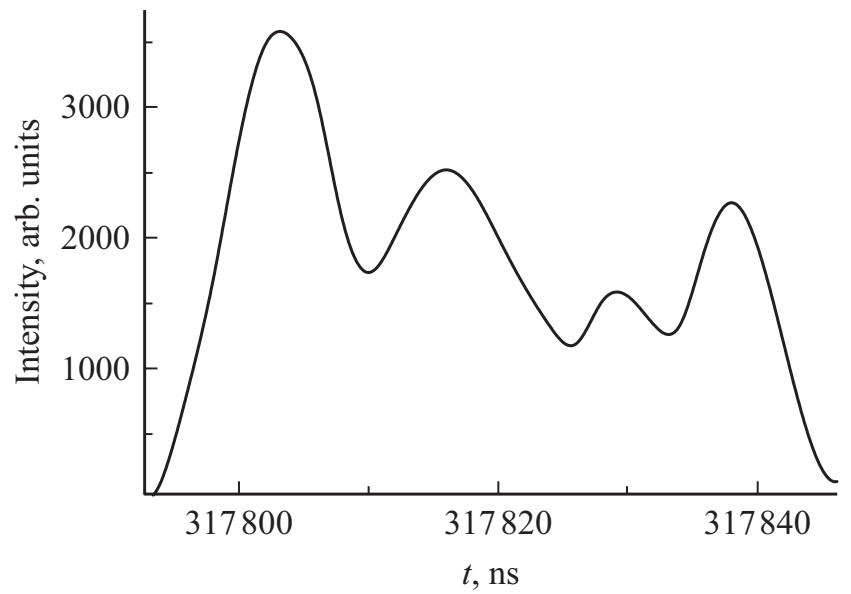

Рис. 6. Типичный сигнал TL.

таких зависимостей позволило найти сигналы, в наименьшей степени искаженные за счет наложения. Один из них показан на рис. 6.

Каждый сигнал длился $\approx 45 \mathrm{~ns}$. Они содержали 4 наложенных друг на друга максимума, возникающих друг за другом через $\approx 10-15 \mathrm{~ns}$.

Как же они образуются? Приложение напряжений к кристаллу вызывает движение дислокаций по плоскостям скольжения. При пересечении этих плоскостей могут образоваться барьеры, препятствующие их движению. При прорыве барьеров, согласно [14], образуются микротрещины. Кристаллическая решетка в моменты прорыва барьеров сильно искажается [15], что может приводить к образованию нанокристаллов на берегах микротрещин. Поэтому образование каждой из микротрещин, на берегах которой располагаются нанокристаллы Si, приводит к появлению максимума в сигнале TL.

Кристалл кремния обладает гранецентрированной кубической (ГЦК) решеткой, и содержит 4 системы плоскостей скольжения дислокаций [111]. Поэтому, ожидалось, что в соответствии с числом плоскостей скольжения сигналы TL должны содержать по 4 максимума, что и наблюдается в действительности.

При образовании каждой из микротрещин в течение некоторого времени происходит релаксация напряжений, что, вероятно, и приводит к появлению следующей микротрещины. В таком случае, временной интервал между максимумами - 10-15 ns соответствует времени, в течение которого перераспределяются напряжения около микротрещины.

\section{6. Заключение}

При трении кристалла кремния о стальной диск в местах пересечения плоскостей скольжения дислокаций образуются барьеры, препятствующие их движению. При прорыве барьеров кристаллическая решетка кремния распадется на нанокристаллы с размерами $\approx 4 \mathrm{~nm}$. 
Одновременно из зоны трения выделяется порошок. Размеры нанокристалла кремния, вероятно, под влиянием внутренних напряжений через несколько часов уменьшаются до $\approx 2.2 \mathrm{~nm}$.

\section{Финансирование работы}

Работа выполнена за счет гранта № 20-05-00155a Российского фонда фундаментальных исследований.

\section{Конфликт интересов}

Авторы заявляют, что у них нет конфликта интересов.

\section{Список литературы}

[1] J. Jakubowicz. In Handbook of Porous Silicon. Ed. L. Canham. (2018). P. 111. Springer Intern. Publ. AG, part of Springer Nature. https://doi.org/10.1007/978-3-319-71381-6_9

[2] Chanika Puridetvorakul, Wandee Onreabroy, Tula Jutarosaga. Songklanakarin J. Sci. Technol. 40, 2, 354 (2018).

[3] M. Gauthier, D. Mazouzi, D. Reyter, B. Lestriez, P. Moreau, D. Guyomard, L. Roué. Energy \& Environmental Sci. 6, 2145 (2013). DOI: 10.1039/C3EE41318G

[4] Rumman Md. Raihanuzzaman, Joon-Woo Song, Ilseuk Lee, Soon-Jik Hong, Jar Myung Koo. Current Nanosci. 10, 3 (2014). DOI: 10.2174/1573413710999140407123913

[5] C. Díaz-Guerra, A. Montone, J. Piqueras, F. Cardellini. Semicond. Sci. Technol. 17, 1, 77 (2002).

Online at stacks.iop.org/SST/17/77

[6] Pushpendra Kumar. Nanotechnology. Article ID 163168, 6 pages (2011) http://dx.doi.org/10.5402/2011/163168

[7] O. Bisi, S. Ossicini, L. Pavesi. Surface Sci. Rep. 38, 1, 126 (2000). DOI: 10.1016/S0167-5729(99)00012-6

[8] M.V. Wolkin, J. Jorne, P.M. Fauchet, G. Allan, C. Delerue. Phys. Rev. Lett. 82, 1, 197 (1999). DOI: https://doi.org/10.1103/PhysRevLett.82.197

[9] J.P. Russell. Appl. Phys. Lett. 6, 11, 223 (1965). https://doi.org/10.1063/1.1754144

[10] I.H. Campbell, P.M. Fauchet. Solid State Commun. 58, 10, 739 (1986). https://doi.org/10.1016/0038-1098(86)90513-2

[11] M.H. Richter, Z.P. Wang., L. Ley. Solid State Commun. 39, 5, 625 (1981). https://doi.org/10.1016/0038-1098(81)90337-9

[12] T. Home, W.B. Kiszenick. Post Appl. Crystallogr. 8, 457 (1975). https://doi.org/10.1107/S0021889875010965

[13] Z. Sui, P.P. Leong, I.P. Herman, G.S. Higashi, H. Temkin. Appl. Phys. Lett. 60, 17, 2086 (1992). https://doi.org/10.1063/1.107364

[14] A.H. Cottrell Theory of Crystal Dislocations. Gordon and Breach, N. Y. (1964). 91 p.

[15] V.A. Zakrevsky, A.V. Shuldiner. Phil. Mag. B 71, 2, 127 (1995).

Редактор Т.Н. Василевская 